\title{
Conference Diary
}

1980

International Components

Show

Reliability Physics

Symposium

30th Electronic

Components Conference

International Hybrid

Microelectronics

Conference

10th European Solid State Device Research Conf.

5th Symposium on Solid State Device Technology

8th Int. Vacuum Congress

4th Int. Conf. on Solid Surfaces

3rd European Conf. on Surface Science

Electronica. Technical

Conf., and Trade Fair

for Components and

Assemblies

\section{International}

Microelectronics

Symposium (sponsored by ISHM)

International Electron

Device Meeting
Paris,

France

Las Vegas,

Nev., U.S.A

San Francisco,

Cal., U.S.A.

April

28-30

Tokyo,

Japan

May 28-30

York,

England

Cannes,

France

Munich,

W. Germany

New York,

U.S.A.

Oct. $20-22$

Washington,

U.S.A.

March 27-

April 2

April 8-10

Sept. $15-19$

Nov. 6-12
Sept. $22-26$

Frau M. Brunner Congress Office, P.O.B. 12 1009, D 8000, Munchen 12.

George D. Lane, Electro Materials Corp. of America, 605 Center Ave., Mamaroneck, N.Y. 10543, U.S.A.

IEEE, 345 East 47 St., New York, N.Y. 10017, U.S.A. 
(Preliminary Announcements)

International Component

Show

European Hybrid

Microelec. Conf.

5th International Thin

Films Conference

Productronica

Hybrid Microelectronics

Conf. (ISHM)
Paris,

France

Avignon,

France

Herzlia,

Israel

Munich,

W. Germany

U.S.A.

Fall
April

April 20-22

Sept. $21-25$

Nov. 9-14
S.D.S.A.,

20 rue Hamelin,

75116, Paris, France.

M. G. Kersuzan,

TRT., 5 Avenue Reaumur, 92350 Le Plessis-Robinson, France.

Prof. N. Klein, Technion, Israel Institute of Technology, Haifa, Israel.

Herr Hans Prieur, Congress Office, POB 12, 1009, D 8000, Munchen 12.

Glen Dowler, ISHM, P.O. 3255, Montgomery, Alabama 36109, U.S.A. 

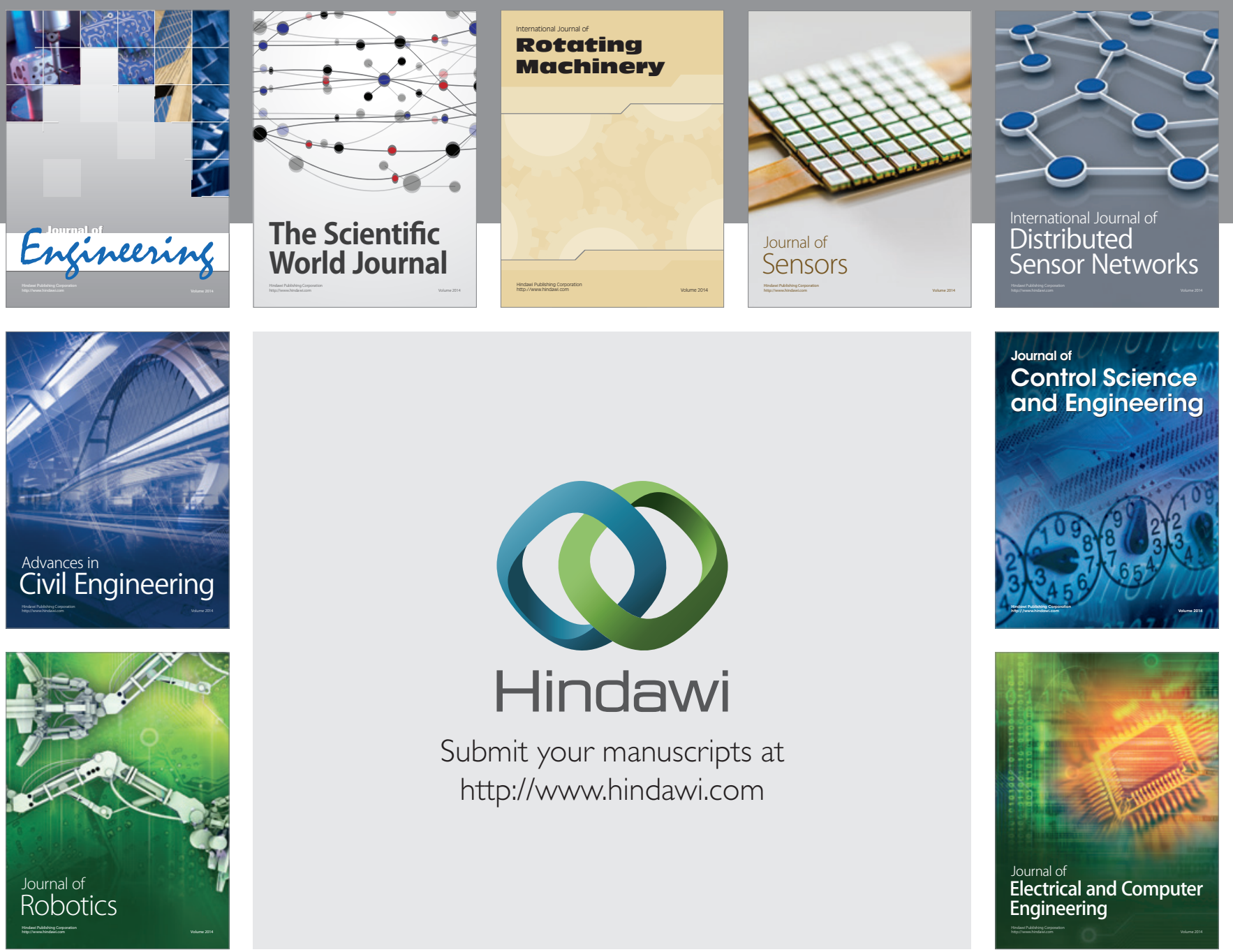

Submit your manuscripts at

http://www.hindawi.com
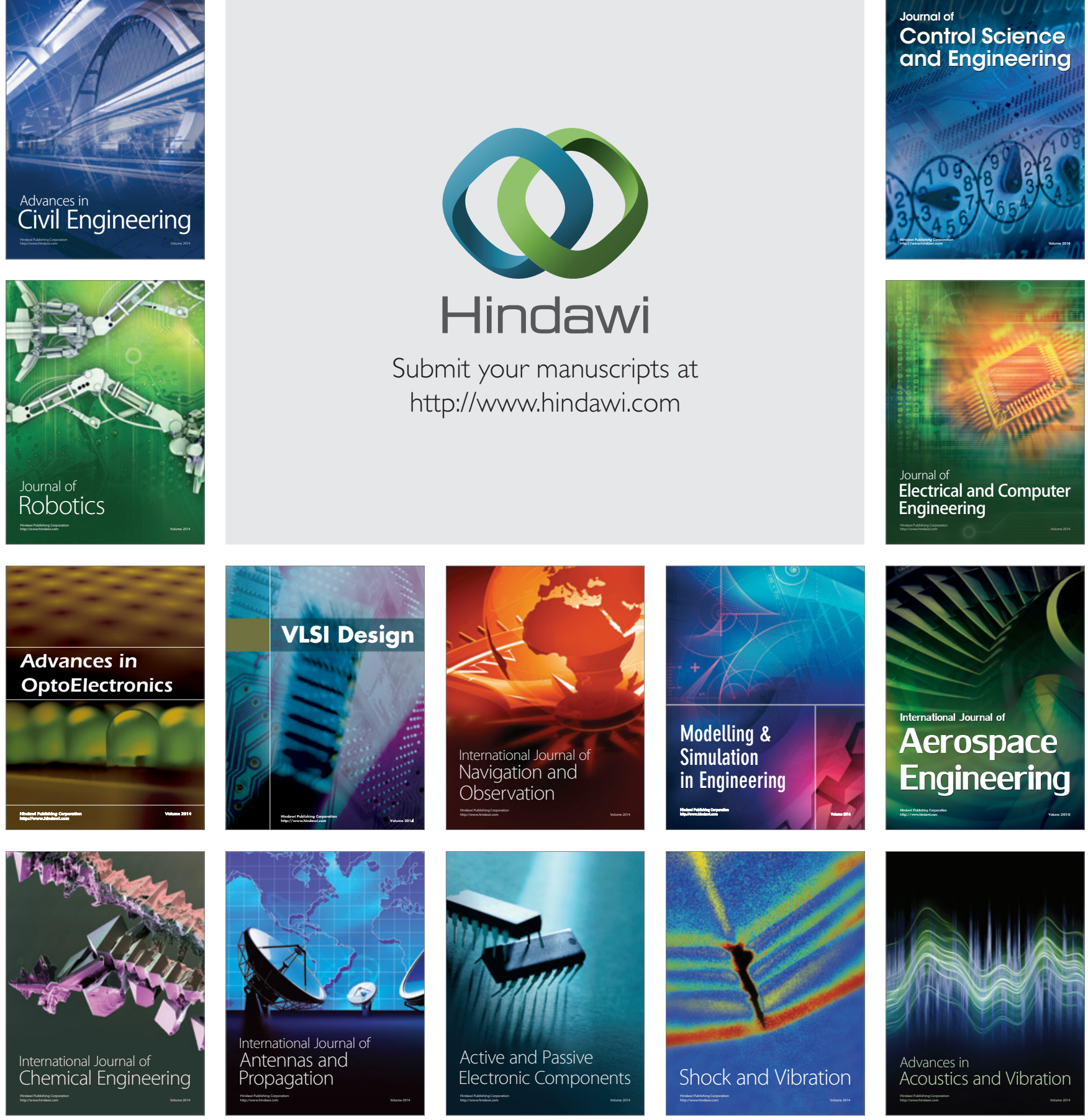